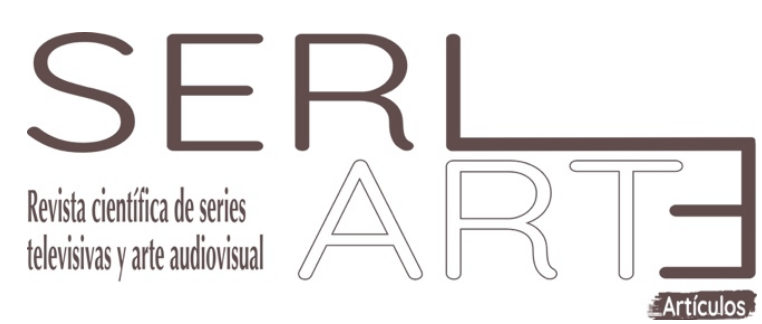

\title{
LA TRADUCCIÓN DEL ARGOT SEXUAL EN SERIES JUVENILES: EL DOBLAJE DE SEX EDUCATION
}

\section{The Translation of Sexual Slang in Teen Series: the Dubbing of SEX EDUCATION}

\author{
María del Mar Ogea Pozo \\ Universidad de Córdoba \\ Irlogpom@uco.es \\ ORCID https://orcid.org/0000-0001-7612-2280 \\ Lara Hidalgo Bujalance \\ Universidad de Córdoba \\ larahidalgobujalance@gmail.com \\ ORCiD https://orcid.org/0000-0002-5739-1298
}

\section{Resumen}

Actualmente, resulta innegable que Netflix se ha instaurado en España como una de las plataformas de contenido en streaming más exitosas del panorama audiovisual. La clave de su éxito es la variedad de producciones disponibles, que satisfacen a suscriptores de todas las edades y grupos sociales. Entre las series más populares entre la población joven destaca Sex Education (2019), que se ha atrevido a representar fielmente el comportamiento y el habla de los adolescentes frente a situaciones cotidianas relacionadas con la sexualidad, reproduciendo su lenguaje sin ningún tipo de tabú. En el presente estudio realizamos un análisis de la traducción (EN-ES) del sociolecto juvenil en lo que 
respecta al argot sexual, con el fin de determinar el registro lingüístico predominante tanto en la cultura británica como en la española, así como los niveles de intensidad de la terminología empleada en ambas lenguas. Finalmente, evaluamos el efecto causado por la presencia del lenguaje sexual entre el público joven español para comprobar si el doblaje proporciona el mismo grado de naturalidad y adecuación del sociolecto, de modo que asegure el éxito de Sex Education entre sus consumidores.

\section{Abstract}

Nowadays, Netflix has clearly established itself in Spain as one of the most successful VOD platforms in the audiovisual scene. The key to its success is the variety of productions available, which satisfy subscribers of all ages and social groups. One of the most popular series among the young population is Sex Education (2019), a series that has dared to faithfully represent the behavior and speech of teenagers in daily situations related to sexuality, reproducing their language with no taboo. In the present study, we conduct an analysis of the translation (EN-ES) of the youth sociolect in terms of sexual slang, in order to determine the predominant linguistic register in both British and Spanish cultures, as well as the levels of intensity of the terminology used in both languages. Finally, we evaluate the impact of sexual slang among the young Spanish audience to ascertain whether dubbing provides the same degree of naturalness and adequacy of the sociolect, so as to ensure the success of Sex Education among its consumers.

\section{Palabras clave}

Series; Sex Education; Lenguaje sexual; Tabú; Lenguaje juvenil; Doblaje; Traducción audiovisual

\section{Keywords}

Series; Sex Education; Sex language; Taboo; Teen slang; Dubbing; Audiovisual translation 


\section{Introducción}

Desde que, en 2015, Netflix se instaurase en España, la plataforma de contenido en streaming se ha convertido en una de las más influyentes del panorama audiovisual nacional y, según el último Anuario SGAE de las artes escénicas, musicales y audiovisuales para 2020, en la que posee un mayor porcentaje de abonados en todos los índices socioeconómicos. Una de las claves de su éxito es la variedad de producciones disponibles en su catálogo, divididas de manera eficiente teniendo en cuenta el género audiovisual, la edad del público potencial o el idioma del contenido, con el fin de optimizar la experiencia al usuario y fidelizar suscriptores de todas las edades y grupos sociales.

Entre los consumidores más activos se encuentran los millenials, hecho que ha motivado el aumento de las conocidas como teen series en el catálogo de la plataforma. Estas producciones se caracterizan por girar en torno a una trama donde la música, el amor, la aventura y las relaciones sociales desempeñan un papel esencial (Guarinos, 2009). En muchas ocasiones, la historia se desarrolla en un entorno estudiantil y refleja sus atributos - grupos sociales, actividades lúdicas, cambios físicos, despertar de la sexualidad-, atributos con los que el espectador puede sentirse identificado, ya sea porque esté viviendo el mismo proceso de madurez que los personajes ficticios (Raya et al., 2018) o porque le haga rememorar esa etapa pasada. Una de las series teen más exitosas del momento es la producción británica Sex Education (Nunn, 2019), la cual se ha atrevido a representar de un modo fiel y natural el comportamiento y el habla de los adolescentes frente a situaciones cotidianas relacionadas con la sexualidad, reproduciendo su lenguaje sin ningún tipo de tabú.

El presente trabajo tiene como finalidad estudiar la presencia del lenguaje sexual en las series juveniles mediante el estudio del caso de Sex Education (2019). Con este fin, se llevará a cabo un análisis de la traducción para doblaje (inglés-español) del sociolecto empleado en dicha producción, en lo que respecta al lenguaje soez, el argot sexual, los eufemismos y los disfemismos, para identificar el registro lingüístico predominante tanto en la cultura británica como en la cultura española a la hora de abordar temas de índole sexual, así como determinar el grado de intensidad de la terminología empleada en ambas 
lenguas. Finalmente, se realizará un estudio de recepción que permita observar el efecto causado por la presencia del lenguaje sexual entre el público en España, con el objetivo de comprobar si el doblaje proporciona el mismo grado de fluidez y adecuación del sociolecto y, por tanto, garantiza la recepción positiva de Sex Education entre los consumidores de la versión traducida.

\subsection{Acerca de Sex Education}

Antes de proceder al análisis de la serie elegida, consideramos necesario presentar algunas de sus características distintivas, las cuales han sido decisivas a la hora de considerar este objeto de estudio como de interés para su investigación.

Sex Education es una serie británica de tipo teen original de Netflix y escrita por Laurie Nunn. Actualmente consta de dos temporadas estrenadas entre 2019 y 2020. La producción ha recibido una crítica muy positiva a nivel internacional por su capacidad de representar fielmente y sin tabús el comportamiento de los adolescentes de hoy en día frente a situaciones reales y cotidianas, prestando atención al lenguaje, las relaciones interpersonales y las inquietudes de los jóvenes con respecto a la sexualidad.

La serie se aleja de las series estereotípicas para adolescentes y refleja la sociedad actual con profundidad y veracidad, mientras cuida aspectos estéticos que la hacen realmente atractiva a los ojos del espectador.

No hay un solo tópico en Sex Education, o más bien es una reunión de todos ellos en posiciones tan absolutamente antagónicas que, a la vez que inventa una nueva forma para la comedia de instituto -la que siempre debería haber existido, aquella en la que todo es posible-, desmonta todas las viejas en un degustable, y plástico -el inacabable colorido del vestuario, la composición de escenas, todo tiene, a ratos, aspecto de viñetafestival narrativo (Fernández, 2020).

En cada episodio encontramos personajes realistas que tratan de afirmar su identidad, desarrollar su autoestima y relacionarse, lo cual resulta en conversaciones con una fuerte carga emocional que debe ser reflejada en la versión traducida.

\subsection{La traducción de Sex Education}

La amplia variedad de temas tratados en la trama deriva en la presencia de textos multidisciplinares, donde se entremezclan términos relacionados con 
distintos campos, registros y sociolectos. Sobresalen dos temas principales: el sexo y las relaciones afectivas/familiares. No obstante, las historias abordan también temas sociales trascendentales como la orientación sexual, el placer femenino, los prejuicios, el bullying, la inclusión social, el feminismo, la sororidad, las agresiones sexuales, las ETS y el aborto. Esta gran variedad de temas es tratada mediante sociolectos especializados - por ejemplo, en boca de Jean, madre de Otis y terapeuta sexual-, desde el registro formal de personales adultos - profesorado y familias- y a través de la jerga juvenil con diferentes niveles de intensidad según la idiosincrasia de cada personaje.

Por último, cabe señalar que el texto tomado para el análisis corresponde con la primera temporada, traducida para doblaje al castellano por Mario Pérez Cuartero. Optamos por esta modalidad de traducción audiovisual debido a su mayor consumo en los territorios de habla española frente al subtitulado. Además, el doblaje resulta de especial interés para el enfoque de nuestro estudio por dos motivos: en primer lugar, porque tiene un impacto directo en las emociones que los espectadores deben experimentar (Ros y Westall, 1996), puesto que se recibe la información de forma más inmediata y natural. Por otro lado, la desaparición del código lingüístico original concede al traductor mayor libertad para emplear técnicas de traducción más creativas, lo cual parece necesario en la traducción de una jerga juvenil fuertemente marcada por la cultura y la evolución natural del lenguaje.

\section{El sociolecto juvenil}

Los cambios en el lenguaje han acompañado a todas las épocas, revoluciones y grandes transformaciones de la sociedad (Rodríguez, 2002: 29). Cada generación adopta palabras, giros, expresiones y neologismos que conforman un lenguaje propio, utilizado como seña de identidad desde el punto de vista sociolingüístico. En el caso del habla juvenil, esta permite a los jóvenes reforzar su permanencia a grupo exclusivo y expresarse mediante «formas no estándares que gozan de un prestigio encubierto entre los miembros del grupoı (Mitkova, 2007) y que «se distingue de la lengua estándar hablada por la gente 'normal'» (Rodríguez, 2002: 34) o de edad más adulta. 
El lenguaje juvenil suscita gran interés desde el punto de vista sociolingüístico, ya que se trata de una variedad lingüística desde el punto léxico, pero también de una fuente de constante enriquecimiento (Mitkova, 2007). Esto se debe a su gran dinamismo, ya que evoluciona y crece con cada grupo generacional por la influencia de modas, formas de pensamiento y moralidad, tabús y estigmas sociales, por la aparición de temas de interés o preocupación para los jóvenes, y por sus preferencias para designar dichos elementos, abierta o sutilmente. Este paso se produce, además, por una búsqueda inconsciente de expresividad, humor e ironía, al igual que por el deseo de convertir la lengua en un instrumento vivo para la comunicación (Santos, 1997: 457). Sus interlocutores engendran palabras nuevas, deforman o infieren nuevos significados a significantes existentes, y toman léxico de sociolectos marginales o lenguas extranjeras (Rodríguez, 2002: 34). Estas unidades léxicas destacan por su valor enfático y connotativo, así como por un carácter que a menudo resulta humorístico y peyorativo (lbid.) y que puede rayar en el vulgarismo y lo soez.

Zimmermann (1996) vincula el lenguaje juvenil a una cultura y a un espacio comunicativo donde no tienen cabida los adultos. Con respecto al empleo y recepción de términos tabú, vulgares y ofensivos, no cabe duda de que estos no producen el mismo impacto en los adolescentes que en los adultos. Este hecho justifica la predilección de los jóvenes por este sistema de comunicación y su consiguiente reflejo en las series de televisión. No obstante, en ocasiones el uso de ciertas unidades léxicas pertenecientes a un sociolecto acaba naturalizándose en el habla cotidiana, lo que provoca que pierda su función primaria de marcadores de grupo y traspasen los límites de su ámbito generacional para formar parte del caudal léxico coloquial de otros grupos de la sociedad (Mitkova, 2007). Esta idea nos interesa especialmente para nuestro estudio, donde podremos encontrar términos sexuales que, si bien se originaron en el marco del sociolecto juvenil, hoy en día forman parte del lenguaje coloquial en un plano más general y ello podría repercutir en la valoración de su intensidad. 


\section{El lenguaje tabú}

El diccionario de la Real Academia Española define el tabú como una «condición de las personas, instituciones y cosas a las que no es lícito censurar o mencionanı. Es decir, concebimos un tabú como algo de lo que no se puede hablar o que no se puede decir, para evitar herir la sensibilidad de otra persona o mostrar una falta de urbanidad. Es evidente que existe un vínculo entre los aspectos socioculturales y lingüísticos del tabú, el cual lo convierte en una «prohibición comunicativa, un comportamiento social de reflejo directo en los actos del habla, que convierte en interdictas determinadas esferası) (Cestero, 2015: 73).

Por otra parte, hemos de entender el concepto de tabú lingüístico como un «fenómeno social, psicológico, cultural y social» (Mayo, 2018: 600) que conlleva la censura parcial o total de determinadas unidades semánticas y léxicas, si bien «el hecho de que existan conceptos tabú no impide que las personas hagamos referencia a ellos» sino que implica una forma particular de expresarlos, alejándonos en mayor o menor medida del significado prohibido (Cestero, 2015: 74). El lenguaje tabú es dinámico y cambiante a nivel social y pragmático, y establece diferencias entre grupos culturales, incluso si estos son hablantes de la misma lengua (Fuentes, 2015). Por consiguiente, está condicionado por aspectos culturales, contextuales y sociales. Cada comunidad construye sus propias expresiones tabú como respuesta a la necesidad de transformación del lenguaje y para facilitar la comunicación, tal y como explican Allan y Burridge:

Taboo and the consequent censoring of language motivate language change by promoting the creation of highly inventive and often playful new expressions, or new meanings for old expressions, causing existing vocabulary to be abandoned. There are basically two ways in which new expressions arise: by a changed form for the tabooed expression and by figurative language sparked by perceptions of and conceptions about the denotata (Allan \& Burridge, 2006: 2).

En muchos casos resulta imposible localizar el origen del carácter restrictivo intrínseco del elemento designado, aunque cabe mencionar que la intención del uso de estos términos también evoluciona. Sánchez (2005) distingue cuatro funciones sociales específicas para las que el lenguaje tabú es introducido en el habla cotidiana: ahuyentar los males; su uso como agresión, humillación o insulto; a modo humorístico o para denotar excitación. De entre esta variedad 
de temas tabú, hay uno que destaca como el gran tabú de la sociedad: las referencias sexuales. De hecho, el autor afirma que «en casi todas las lenguas hay palabras obscenas que se consideran indecentes y ofensivas para la moralidad sexual aceptada») (Sánchez, 2005). El gran impacto sociocultural que genera este tipo de tabú y las alteraciones que se puedan producir durante la traducción son la motivación principal de este estudio.

\subsection{El lenguaje sexual en las series}

Durante el transcurso del siglo XXI, nuestra sociedad ha sido testigo de cambios socioculturales sin precedentes. A pesar de que hoy en día millones de personas siguen reivindicando la libertad de expresión a través de las redes sociales o mediante movilizaciones en lugares públicos, el sexo, el erotismo y las referencias sexuales siguen constituyendo hoy algunos de los temas más eludidos. Resulta imposible negar el pudor que envuelve estas cuestiones consideradas como obscenas y desprovistas de vergüenza. Surià (2014) cita unas líneas del Diccionario del sexo y erotismo, por Félix Rodríguez (2011), donde este afirma que vivimos en tiempos de mayor libertad, pero a pesar de ello, todavía muchos ven el sexo como algo intrínsecamente malo, y su invocación les hace sentir ofendidos e incómodos. La actividad sexual sometida a censura social se convierte, por tanto, en un tema que se enfrenta a restricciones lingüísticas y que da lugar a la creación de nuevas expresiones y significados, así como al uso del lenguaje figurado y juegos verbales para hacer referencia al placer sexual y el acto de copulación (Allan y Burridge, 2006). No obstante, a pesar de su condición de tabú, la mayoría de las lenguas contienen un vasto número de referencias sexuales en su vocabulario que sus hablantes utilizan diariamente y que están relacionadas con aspectos culturales tales como el grado de tolerancia hacia el tema, la posible interpretación por parte del receptor y el significado adquirido en la lengua.

En el ámbito audiovisual, la temática sexual ha experimentado un cambio constante, aunque siempre ha estado rodeada de polémicas. Si bien muchos cineastas han recurrido a escenas de contenido sexual y al lenguaje tabú como reclamo para llamar la atención del público, es innegable que existe un enorme pudor a mostrar o decir más de la cuenta (Zorrilla, 2015; Fuentes, 2015). A pesar de ello, la perspectiva del sexo, el amor y las relaciones sociales en el cine ha 
MARÍA DEL MAR OGEA POZO Y LARA HIDALGO BUJALANCE

cambiado enormemente a medida que se han normalizado dichos temas entre las nuevas generaciones.

En la actualidad, es fácil encontrar producciones audiovisuales que retratan la realidad social en torno a las prácticas sexuales y el erotismo, como Masters of Sex (2013), O Negócio (2013), Modern Love (2019), Sex/Life (2021) y Valeria (2020), entre otras muchas. En cuanto a las series dirigidas a adolescentes, estas se distinguen por contener una mayor cantidad de vocabulario de naturaleza sexual perteneciente al registro coloquial, vulgar y, en ocasiones, ofensivo, entre las cuales conviene destacar series como Girls (2012), Skins (2007), Euphoria (2019) y Sex Education (2019), siendo esta última el objeto del presente estudio. Los diálogos que conforman la trama de estas series están repletos de terminología de temática sexual que reflejan el discurso cotidiano de la población más joven. A través de este «discurso audiovisual hablado» se vehiculizan aspectos como el nivel sociocultural, el origen geográfico o étnico (Fuentes, 2015), la edad del hablante y las corrientes de contracultura o subcultura con las que los espectadores pueden sentirse identificados.

En las series que conciernen principalmente a los jóvenes, como es el caso de Sex Education, es frecuente encontrarnos con eufemismos y disfemismos que reflejan un registro familiar o coloquial (Alan y Burridge, 2006). La diferencia entre estos recursos reside en el grado de aceptabilidad de ambos, ya que los eufemismos corresponden a un uso informal y figurado del lenguaje que evita la obscenidad, mientras que los disfemismos reflejan un uso más grotesco o humorístico de la palabra tabú (Surià, 2014). Asimismo, en los diálogos de las series juveniles también es posible identificar el uso del ortofemismo como medio para denotar la información de manera directa. Para ejemplificar la diferencia entre estos recursos, podríamos distinguir el ortofemismo ejaculate, el eufemismo come y el disfemismo spunk dentro del mismo campo temático.

Ante lo anteriormente expuesto, la cuestión sobre la que debemos reflexionar es la relación entre la edad del hablante y el tipo variación lingüística a la que se va a recurrir según la situación comunicativa y el tipo vocabulario empleado. A la hora de abordar un tema de naturaleza sexual, el nivel sociolingüístico del hablante en cuestión, además de la variedad diafásica o registro que desee utilizar, tendrán una gran incidencia en el discurso y, por consiguiente, en la forma en que debe ser traducido. 


\subsection{Tipología del tabú lingüístico}

Con el fin de proceder a la selección de términos tabú en la serie analizada, debemos establecer un modelo de clasificación que nos permita compilar y ordenar el corpus bilingüe, donde las unidades léxicas queden agrupadas según la temática y el concepto que designan.

Aunque son escasos, existen varios estudios que han aportado taxonomías de los principales sistemas de referencia del lenguaje tabú: Ávila (2004) elabora una clasificación por campos semánticos, Cestero (2015) propone un modelo de identificación de las realidades tabú que comprende cuatro esferas interdictas, y Fuentes (2015) categoriza los conceptos utilizados en las lenguas de trabajo más comunes en la traducción audiovisual. Dichos estudios tratan el lenguaje tabú en su sentido más amplio, incluyendo expresiones interdictas en distintas comunidades culturales que van más allá del erotismo y la sexualidad. Por este motivo, para este estudio resultan especialmente relevantes los trabajos de Allan y Burridge (2006) y de Surià (2014). Los primeros llevan a cabo un exhaustivo estudio sobre el lenguaje tabú que distingue tres macrogrupos: Sex and bodily effluvia, Food and smell, y Disease, death and killing. El capítulo dedicado al vocabulario de temática sexual incluye los siguientes tipos de términos tabuizados:

\begin{tabular}{|c|}
\hline $\begin{array}{c}\text { Act of sex } \\
\text { Gender and sexuality } \\
\text { Masturbation } \\
\text { Oral sex } \\
\text { Orgasm }\end{array}$ \\
\hline $\begin{array}{c}\text { Homosexuality and queer } \\
\text { Bodily functions and effluvia } \\
\text { Menstruation }\end{array}$ \\
\hline
\end{tabular}

Tabla 1. Tipología del lenguaje sexual de Allan y Burridge (2006).

En cuanto a la tipología elaborada por Surià (2014), la autora distingue cinco temáticas que originan las palabras que conforman el argoł sexual: 
MARÍA DEL MAR OGEA POZO Y LARA HIDALGO BUJALANCE

\begin{tabular}{|c|}
\hline Acto sexual \\
\hline Pene \\
\hline Vagina \\
\hline Pechos \\
\hline Otras etimologías \\
\hline
\end{tabular}

Tabla 2. Tipología del argot sexual de Surià (2014).

A partir de estas propuestas, elaboraremos un modelo de clasificación que responda a las necesidades específicas de nuestro estudio según las características de las unidades tabú de índole sexual halladas en el texto audiovisual seleccionado y que será descrito en el apartado «Metodología».

\section{La traducción de las palabras tabú de tipo sexual}

Cada lengua y cada cultura emplea sistemas de referencia distintos para expresar el lenguaje tabú, incluso alberga sistemas de referencia diferentes para designar ciertas realidades (Fuentes, 2015). En el texto audiovisual, los diálogos pretenden reflejar la oralidad propia del habla cotidiana (Pujol, 2006: 131) y, por tanto, la traducción debe causar el mismo efecto entre el público de la lengua y la cultura de llegada, a pesar de las limitaciones específicas de la traducción audiovisual —como la subordinación a la imagen, la sincronía o la limitación espacial, entre otras-. Es fundamental que el traductor audiovisual identifique y evalúe el impacto y la carga emocional de cada término o expresión hallado en la versión original, con el fin de trasvasar dicha unidad a la lengua y cultura de llegada haciendo uso del equivalente funcional más apropiado para ese contexto específico (Díaz-Cintas y Remael, 2007: 196). El traductor debe, pues, guiarse por la naturaleza del texto y encontrar una solución aceptable a la situación comunicativa que está presenciando (Bernal, 2018: 78). No todo aquello que resulta aceptable en una cultura origen lo es en la cultura meta, y por ello el traductor debe prestar atención a aquellos elementos susceptibles de causar cualquier tipo de controversia o malestar entre la audiencia.

Con el objeto de evitar cualquier conflicto sociocultural, en numerosas ocasiones el traductor experimenta de forma tanto consciente como inconsciente la autocensura que nos ha sido implícitamente impuesta 
(Santaemilia, 2008) mediante la eliminación o atenuación de los términos sexuales, transfiriendo a su reescritura el nivel de aceptabilidad de su propia moral (Surià, 2014). Esta solución resulta poco recomendable, especialmente en el caso de series de temática sexual y adolescente, cuyo público espera sentirse identificado al encontrarse rodeado de un lenguaje que es la seña que lo distingue de otras comunidades de hablantes. Por tanto, es crucial que los términos tabú se traduzcan respetando la caracterización y función de los mismos en el film (Díaz-Cintas y Remael, 2007: 197). Además, no debemos olvidar la importancia de crear un "efecto realidad» (Chaume, 2005: 145) en el texto audiovisual traducido, es decir, obtener un discurso fluido y verosímil que propicia la ilusión cinematográfica de que los diálogos fueron creados en la lengua en la que el espectador visiona la serie.

No obstante, la atenuación o intensificación de la carga emocional del lenguaje tabú puede atender a diferencias en cuanto a los niveles de aceptabilidad de las culturas implicadas. Estas variaciones pueden verse reflejadas a través de eufemismos, disfemismos, modificaciones, omisiones o adiciones que pretendan aportar una traducción satisfactoria para los receptores. La elección de una u otra técnica mantiene una estrecha relación con la cultura implicada. Sánchez (2005) sostiene que en la lengua inglesa se tiende a suavizar a través de eufemismos y disfemismos aquellos términos que hagan referencia tanto al acto sexual como a los genitales. Estas expresiones deben conservar un ápice de ambigüedad para ser interpretados tanto en el sentido sexual como en el secundario. Por el contrario, a la hora de hacer uso del lenguaje sexual en español, generalmente no se manifiesta la necesidad de recurrir a eufemismos en la misma medida. En un análisis de la traducción español-inglés de cuatro obras de Vargas Llosa, Santaemilia (2010) descubrió una evidente disimilitud entre la alta intensidad del contenido sexual en la versión original y la versión traducida en inglés, siendo esta última considerablemente rica en eufemismos desprovistos de toda dimensión emocional.

Así pues, no cabe duda de que, para propiciar una comunicación adaptada a estas limitaciones socioculturales, es indispensable conocer el significado preciso de estos términos sexuales y las situaciones socioculturales en las que 
procede utilizarlos, con el objetivo de transmitir la información adecuadamente y asegurar el disfrute de los espectadores.

\section{Metodología del estudio}

Tras el visionado de la serie tanto en su versión original en inglés como en su versión doblada al español, hemos compilado un corpus bilingüe (EN-ES) con unidades extraídas de la primera temporada, constituida por un total de 8 episodios que en conjunto suman una duración aproximada de 396 minutos. En dicho corpus se recogen 209 entradas que contienen algún tipo de connotación sexual, de las cuales se han seleccionado finalmente 118 unidades lingüísticas para su estudio.

Con el fin de estructurar adecuadamente el análisis, se ha estudiado la naturaleza semántica de las unidades seleccionadas, las cuales han quedado agrupadas en distintas categorías, a saber:

- Terminología relacionada con el acto sexual

- Terminología relacionada con los genitales (masculinos/femeninos)

- Terminología relacionada con la masturbación

- Terminología relacionada con las secreciones sexuales

- Procesos de la sexualidad

Posteriormente, se ha elaborado un modelo de clasificación conforme a los distintos grados de intensidad que las unidades recopiladas podrían tener atribuidos:

- Ofensivo

- Malsonante/vulgar

- Coloquial

- Normal

- Formal

Posteriormente se ha procedido a la elaboración de un sondeo por medio de un formulario de Google en el que los encuestados debían seleccionar el nivel de intensidad que percibían en las distintas unidades lingüísticas expuestas y ordenadas según las categorías previamente mencionadas. En total se 
reunieron un total de 120 respuestas enviadas por traductores profesionales, estudiantes de los grados de Traducción e Interpretación y de Estudios Ingleses, y otros usuarios con conocimientos de idiomas, que no necesariamente habrían visto la serie en cuestión.

Tras examinar los resultados obtenidos en el sondeo, se ha efectuado un análisis de frecuencia de uso y el registro lingüístico de las unidades compiladas para determinar qué es predominante en cada cultura.

\section{Análisis y resultados}

A continuación, mostraremos parte de los resultados del análisis de la traducción de Sex Education. Debido a la extensión del corpus, limitaremos este estudio a la exposición de los ejemplos más representativos de cada categoría y cuyo uso es más recurrente en ambas lenguas. Hemos de aclarar que dichos términos no siempre han sido traducidos mediante el mismo equivalente en español, por tanto, no hemos establecido un paralelismo entre las unidades seleccionadas en ambas lenguas, sino una comparación entre el número de unidades empleadas en el texto original y el texto meta, con el fin de valorar el grado de intensidad que predomina en cada versión.

- Terminología relacionada con el acto sexual

\begin{tabular}{|c|c|c|c|c|c|}
\hline Unidad lingüística & Ofensivo & $\begin{array}{l}\text { Malsonante/ } \\
\text { vulgar }\end{array}$ & Coloquial & Normal & Formal \\
\hline To shag & $8,3 \%$ & $49,6 \%$ & $39,7 \%$ & $2,5 \%$ & $0 \%$ \\
\hline To bone & $14,9 \%$ & $46,3 \%$ & $34,7 \%$ & $4,1 \%$ & $0 \%$ \\
\hline To fuck & $7,4 \%$ & $47,1 \%$ & $31,4 \%$ & $14 \%$ & $0 \%$ \\
\hline To have sex & $0,8 \%$ & $0,8 \%$ & $9,1 \%$ & $54,5 \%$ & $34,7 \%$ \\
\hline To hook up & $4,1 \%$ & $20,7 \%$ & $57,9 \%$ & $16,5 \%$ & $0,8 \%$ \\
\hline To sleep with s/o & $0,8 \%$ & $0,8 \%$ & $8,3 \%$ & $50,4 \%$ & $39,7 \%$ \\
\hline $\begin{array}{l}\text { To put his bits in } \\
\text { her bits }\end{array}$ & $13,2 \%$ & $24,8 \%$ & $52,9 \%$ & $5,8 \%$ & $3,3 \%$ \\
\hline Intercourse & $0,8 \%$ & $5,0 \%$ & $8,3 \%$ & $9,9 \%$ & $76 \%$ \\
\hline Sex & $0,8 \%$ & $0,8 \%$ & $6,6 \%$ & $71,1 \%$ & $20,7 \%$ \\
\hline Sexual relation & $0,8 \%$ & $0,8 \%$ & $2,5 \%$ & $34,7 \%$ & $61,2 \%$ \\
\hline
\end{tabular}




\begin{tabular}{|l|r|r|r|r|r|}
\hline To fornicate & $7,4 \%$ & $19,8 \%$ & $6,6 \%$ & $10,7 \%$ & $55,4 \%$ \\
\hline To get to the sex & $5,8 \%$ & $9,1 \%$ & $50,4 \%$ & $24,8 \%$ & $9,9 \%$ \\
\hline
\end{tabular}

Tabla 3. Terminología relacionada con el acto sexual (EN).

\begin{tabular}{|c|c|c|c|c|c|}
\hline Unidad lingüística & Ofensivo & $\begin{array}{l}\text { Malsonante/ } \\
\text { vulgar }\end{array}$ & Coloquial & Normal & Formal \\
\hline Mojar & $5 \%$ & $42,1 \%$ & $52,1 \%$ & $0,8 \%$ & $0 \%$ \\
\hline Follar & $5,8 \%$ & $57,9 \%$ & $29,8 \%$ & $6,6 \%$ & $0 \%$ \\
\hline $\begin{array}{l}\text { Acostarse con } \\
\text { alguien }\end{array}$ & $0,8 \%$ & $0,8 \%$ & $13,2 \%$ & $63,6 \%$ & $21,5 \%$ \\
\hline Enrollarse & $0,8 \%$ & $0,8 \%$ & $64,5 \%$ & $33,9 \%$ & $0 \%$ \\
\hline Tener relaciones & $0,8 \%$ & $0,8 \%$ & $1,7 \%$ & $21,5 \%$ & $75,2 \%$ \\
\hline Hacerlo & $1,7 \%$ & $0 \%$ & $39,7 \%$ & $51,2 \%$ & $7,4 \%$ \\
\hline Fornicar & $7,4 \%$ & $27,3 \%$ & $9,1 \%$ & $8,3 \%$ & $47,9 \%$ \\
\hline Sexo & $0,8 \%$ & $0,8 \%$ & $5,8 \%$ & $75,2 \%$ & $17,4 \%$ \\
\hline Polvo & $0,8 \%$ & $24,8 \%$ & $72,7 \%$ & $0,8 \%$ & $0,8 \%$ \\
\hline Tirarse a alguien & $22,3 \%$ & $33,1 \%$ & $43,8 \%$ & $0,8 \%$ & $0 \%$ \\
\hline Coito & $0,8 \%$ & $1,7 \%$ & $0 \%$ & $1,7 \%$ & $95,9 \%$ \\
\hline Polvazo & $10,7 \%$ & $44,6 \%$ & $42,1 \%$ & $2,5 \%$ & $0 \%$ \\
\hline Ir al lío & $3,3 \%$ & $13,2 \%$ & $68,6 \%$ & $14 \%$ & $0,8 \%$ \\
\hline Revolcón & $9,1 \%$ & $23,1 \%$ & $57,9 \%$ & $9,1 \%$ & $0,8 \%$ \\
\hline
\end{tabular}

Tabla 4. Terminología relacionada con el acto sexual (ES).

A lo largo de la primera temporada hemos podido comprobar cómo en numerosas ocasiones los personajes hacen referencia al acto sexual, siendo este efectivamente el objeto central de la trama. Como consecuencia, se han recogido en nuestro corpus un total de 54 entradas en inglés y 53 entradas en español que hacen referencia al sexo como actividad.

Como podemos observar en las tablas arriba expuestas, en la versión inglesa hallamos un total de 12 unidades, mientras que en la versión doblada se hizo uso de 14 términos para designar el acto sexual. Esto puede explicarse porque se ha detectado una alternancia de los términos elegidos durante el proceso de traducción. Por ejemplo, observamos que to fuck ha sido traducido mediante el uso de su equivalente más directo (follar) pero también como acostarse con alguien. Por otro, lado, la palabra follar ha sido recurrente para traducir al 
español distintas unidades: to have sex, to fuck y to shag. Resulta evidente, pues, cierta disparidad que puede responder a la necesidad de evitar repeticiones de la misma palabra en el discurso en español, aportando una mayor riqueza léxica en esta lengua.

No obstante, si nos centramos en los datos obtenidos de la encuesta, percibimos ciertas disimilitudes en cuanto al grado de intensidad en ambos textos. A pesar de que los encuestados opinaron que la presencia de términos interpretados como malsonantes, coloquiales y normales era similar en ambos textos audiovisuales, existe un grado de formalidad menor en la versión en español, donde llama la atención el elevado porcentaje de encuestados (22,3\%) que valoraron la carga ofensiva de uno de los términos (tirarse a). Podemos concluir que el grado de intensidad difiere entre las dos lenguas implicadas, aunque ambas presentan principalmente rasgos de coloquialidad y carga soez propio del sociolecto juvenil. Por otro lado, cabe mencionar que el uso de ortofemismos que aportan formalidad al discurso es mayor en inglés, mientras que en español se detecta un uso puntual de disfemismos (tirarse a, polvazo, revolcón) que pueden ser interpretados como ofensivos o coloquiales en mayor medida que sus equivalentes funcionales en inglés (to have sex, sex, to get to the sex).

- Terminología relacionada con genitales masculinos

Llegados a este punto resulta razonable pensar que las expresiones relacionadas con los genitales tienen una fuerte presencia en el texto audiovisual. Para realizar un análisis correctamente estructurado de la terminología, optamos por separar los genitales masculinos y los genitales femeninos para su estudio.

\begin{tabular}{|l|r|r|r|r|r|}
\hline $\begin{array}{l}\text { Unidad } \\
\text { lingüística }\end{array}$ & Ofensivo & Malsonante/vulgar & Coloquial & Normal & Formal \\
\hline Penis & $0,8 \%$ & $1,7 \%$ & $4,1 \%$ & $33,9 \%$ & $59,5 \%$ \\
\hline Dick & $1,7 \%$ & $33,1 \%$ & $49,6 \%$ & $15,7 \%$ & $0 \%$ \\
\hline Knob & $3,3 \%$ & $52,9 \%$ & $39,7 \%$ & $4,1 \%$ & $0 \%$ \\
\hline Whale dick & $24,8 \%$ & $60,3 \%$ & $14 \%$ & $0,8 \%$ & $0 \%$ \\
\hline Cock & $7,4 \%$ & $51,2 \%$ & $36,4 \%$ & $4,1 \%$ & $0,8 \%$ \\
\hline
\end{tabular}




\begin{tabular}{|l|r|r|r|r|r|}
\hline Phallus & $1,7 \%$ & $8,3 \%$ & $4,1 \%$ & $6,6 \%$ & $79,3 \%$ \\
\hline Prick & $8,3 \%$ & $40,5 \%$ & $38 \%$ & $11,6 \%$ & $1,7 \%$ \\
\hline
\end{tabular}

Tabla 5. Terminología relacionada con los genitales masculinos (EN).

\begin{tabular}{|l|r|r|r|r|r|}
\hline $\begin{array}{l}\text { Unidad } \\
\text { lingüística }\end{array}$ & Ofensivo & Malsonante/vulgar & Coloquial & Normal & Formal \\
\hline Rabo & $8,3 \%$ & $66,1 \%$ & $24 \%$ & $1,7 \%$ & $0 \%$ \\
\hline Polla & $5,8 \%$ & $45,5 \%$ & $38,8 \%$ & $9,9 \%$ & $0 \%$ \\
\hline Pollón & $20,7 \%$ & $66,9 \%$ & $11,6 \%$ & $0,8 \%$ & $0 \%$ \\
\hline Pene & $0,8 \%$ & $0,8 \%$ & $2,5 \%$ & $46,3 \%$ & $49,6 \%$ \\
\hline Falo & $0,8 \%$ & $14 \%$ & $10,7 \%$ & $9,1 \%$ & $65,3 \%$ \\
\hline Verga & $3,3 \%$ & $43,8 \%$ & $43,8 \%$ & $5,8 \%$ & $3,3 \%$ \\
\hline
\end{tabular}

Tabla 6. Terminología relacionada con los genitales masculinos (ES).

El análisis de frecuencia ha revelado que los términos con más repeticiones a lo largo del mismo son dick en inglés y polla en español con 19 y 26 repeticiones, respectivamente. Observamos, pues, una clara disparidad entre el número repeticiones de ambos términos, lo que descarta que este par de términos sean equivalentes exclusivos. No obstante, según el sondeo realizado, ambos poseen niveles de intensidad similares, si bien la acepción en español es considerada como malsonante por un mayor número de participantes (45,5\% frente a $33,1 \%)$.

En base al resto de los resultados obtenidos, todo apunta a que nos encontramos ante cierta atenuación del lenguaje sexual en el contexto social británico pues, aunque observamos porcentajes similares de usuarios que catalogan dos de los términos como normales o formales en cada lengua (penis y phallus frente a pene y falo), sí descubrimos cierta disimilitud en cuanto al predominio del tono malsonante, vulgar o coloquial, siendo este más acusado en español.

- Terminología relacionada con los genitales femeninos

\begin{tabular}{|l|r|r|r|r|r|}
\hline $\begin{array}{l}\text { Unidad } \\
\text { lingüística }\end{array}$ & Ofensivo & Malsonante/vulgar & Coloquial & Normal & Formal \\
\hline Minge & $3,3 \%$ & $49,6 \%$ & $32,2 \%$ & $12,4 \%$ & $2,5 \%$ \\
\hline Vagina & $0,8 \%$ & $0,8 \%$ & $3,3 \%$ & $40,5 \%$ & $54,5 \%$ \\
\hline Clit & $0 \%$ & $8,3 \%$ & $30,6 \%$ & $43 \%$ & $18,2 \%$ \\
\hline
\end{tabular}




\begin{tabular}{|l|r|r|r|r|r|}
\hline Lady bits & $9,9 \%$ & $23,1 \%$ & $49,6 \%$ & $8,3 \%$ & $9,1 \%$ \\
\hline Sashimi & $28,1 \%$ & $44,6 \%$ & $24,8 \%$ & $0,8 \%$ & $1,7 \%$ \\
\hline Vag & $1,7 \%$ & $18,2 \%$ & $67,8 \%$ & $10,7 \%$ & $1,7 \%$ \\
\hline Labia & $0,8 \%$ & $11,6 \%$ & $15,7 \%$ & $17,4 \%$ & $54,5 \%$ \\
\hline Flaps & $14 \%$ & $48,8 \%$ & $29,8 \%$ & $5,8 \%$ & $1,7 \%$ \\
\hline Beef curtains & $59,5 \%$ & $28,1 \%$ & $12,4 \%$ & $0 \%$ & $0 \%$ \\
\hline Vulva & $0,8 \%$ & $0,8 \%$ & $2,5 \%$ & $16,5 \%$ & $79,3 \%$ \\
\hline
\end{tabular}

Tabla 7. Terminología relacionada con los genitales femeninos (EN).

\begin{tabular}{|l|r|r|r|r|r|}
\hline $\begin{array}{l}\text { Unidad } \\
\text { lingüística }\end{array}$ & Ofensivo & Malsonante/vulgar & Coloquial & Normal & Formal \\
\hline Coño & $8,3 \%$ & $61,2 \%$ & $25,6 \%$ & $5 \%$ & $0 \%$ \\
\hline Vagina & $0,8 \%$ & $1,7 \%$ & $2,5 \%$ & $38 \%$ & $57 \%$ \\
\hline Clítoris & $0,8 \%$ & $0,8 \%$ & $2,5 \%$ & $55,4 \%$ & $40,5 \%$ \\
\hline Sashimi & $26,4 \%$ & $42,1 \%$ & $27,3 \%$ & $3,3 \%$ & $0,8 \%$ \\
\hline Chocho & $5 \%$ & $47,9 \%$ & $44,6 \%$ & $2,5 \%$ & $0 \%$ \\
\hline Chichi & $0,8 \%$ & $27,3 \%$ & $66,1 \%$ & $5,8 \%$ & $0 \%$ \\
\hline Potorro & $11,6 \%$ & $62,8 \%$ & $25,6 \%$ & $0 \%$ & $0 \%$ \\
\hline Labios & $2,5 \%$ & $6,6 \%$ & $16,5 \%$ & $41,3 \%$ & $33,1 \%$ \\
\hline Colgajos & $69,4 \%$ & $25,6 \%$ & $4,1 \%$ & $0,8 \%$ & $0 \%$ \\
\hline Vulva & $0,8 \%$ & $2,5 \%$ & $3,3 \%$ & $20,7 \%$ & $72,7 \%$ \\
\hline
\end{tabular}

Tabla 8. Terminología relacionada con los genitales femeninos (ES).

Tras realizar el análisis de frecuencia de uso de estas unidades se confirmó la existencia de un total de 26 entradas en inglés y 25 entradas en español. Entre estas, el término vagina en inglés, con 12 repeticiones, y coño en español, con 8 repeticiones, constituyen las entradas más reiteradas a lo largo del texto audiovisual, mostrando cierta desigualdad en cuanto al nivel de intensidad en ambas versiones. A pesar de hallar porcentajes similares en cuanto a la carga emocional del par de términos equivalentes beef curtains y colgajos, considerados mayoritariamente como ofensivos en ambas lenguas, en términos generales observamos una mayor carga peyorativa en el lenguaje sexual empleado en español, donde las cifras muestran dos términos marcados como malsonantes por más del $60 \%$ de los participantes (coño, potorro) y otros dos por más del 40\% (sashimi, chocho). En contraposición, los resultados indican una 
mayor frecuencia del lenguaje coloquial en inglés (con términos como vag), lo cual prueba un menor grado de informalidad y carga soez.

Por consiguiente, los datos expuestos en la tabla demuestran la prevalencia de la atenuación y el uso de eufemismos en inglés en comparación con el español. No obstante, existen unidades que, aunque no sean tan recurrentes en el habla juvenil cotidiana, poseen niveles de intensidad semejantes.

- Terminología relacionada con la masturbación

\begin{tabular}{|l|r|r|r|r|r|}
\hline $\begin{array}{l}\text { Unidad } \\
\text { lingüística }\end{array}$ & Ofensivo & Malsonante/vulgar & Coloquial & Normal & Formal \\
\hline Handjob & $0 \%$ & $16,5 \%$ & $61,2 \%$ & $20,7 \%$ & $1,7 \%$ \\
\hline To masturbate & $0,8 \%$ & $0,8 \%$ & $4,1 \%$ & $43 \%$ & $51,2 \%$ \\
\hline To stroke a & $5,8 \%$ & $35,5 \%$ & $36,4 \%$ & $16,5 \%$ & $5,8 \%$ \\
\hline penis & $12,4 \%$ & & & & \\
\hline To flick the & & $42,1 \%$ & $44,6 \%$ & $0,8 \%$ & $0 \%$ \\
\hline bean & $1,7 \%$ & $52,9 \%$ & $35,5 \%$ & $6,6 \%$ & $0 \%$ \\
\hline To wank & $2,5 \%$ & $5,8 \%$ & $8,3 \%$ & $15,7 \%$ & $68,6 \%$ \\
\hline Fellatio & $1,7 \%$ & $17,4 \%$ & $71,1 \%$ & $9,1 \%$ & $0 \%$ \\
\hline BJ & $1,7 \%$ & $12,4 \%$ & $67,8 \%$ & $16,5 \%$ & $1,7 \%$ \\
\hline To go down & $5 \%$ & $23,1 \%$ & $56,2 \%$ & $17,4 \%$ & $1,7 \%$ \\
\hline Blowjob & $10,7 \%$ & $48,8 \%$ & $38 \%$ & $8,3 \%$ & $0 \%$ \\
\hline To suck off & $0,8 \%$ & $37,2 \%$ & $33,9 \%$ & $18,2 \%$ & $0 \%$ \\
\hline To suck a dick & $0,8 \%$ & $21,5 \%$ & $47,9 \%$ & $27,3 \%$ & $2,5 \%$ \\
\hline To finger & Tabla $\%$ Terminología relacionada con la masturbación (EN). & \\
\hline To touch & $1,7 \%$ & $20,7 \%$ & $52,9 \%$ & $24 \%$ \\
\hline
\end{tabular}

\begin{tabular}{|l|r|r|r|r|r|}
\hline Unidad lingüísti & Ofensivo & Malsonante/vulgar & Coloquial & Normal & Formal \\
\hline Hacer una paja & $0,8 \%$ & $24,6 \%$ & $63,6 \%$ & $9,1 \%$ & $0 \%$ \\
\hline Chuparla & $5,8 \%$ & $38,8 \%$ & $48,8 \%$ & $6,6 \%$ & $0 \%$ \\
\hline Masturbarse & $0,8 \%$ & $1,7 \%$ & $5,8 \%$ & $65,3 \%$ & $26,4 \%$ \\
\hline Felación & $0,8 \%$ & $2,5 \%$ & $4,1 \%$ & $11,6 \%$ & $81 \%$ \\
\hline Bajar & $1,7 \%$ & $14,9 \%$ & $61,2 \%$ & $22,3 \%$ & $0 \%$ \\
\hline Comérsela/o & $6,6 \%$ & $32,2 \%$ & $55,4 \%$ & $5,8 \%$ & $0 \%$ \\
\hline
\end{tabular}




\begin{tabular}{|l|r|r|r|r|r|}
\hline Mamada & $8,3 \%$ & $44,6 \%$ & $38 \%$ & $8,3 \%$ & $0,8 \%$ \\
\hline Dedos & $0 \%$ & $18,2 \%$ & $52,1 \%$ & $28,9 \%$ & $0,8 \%$ \\
\hline
\end{tabular}

Tabla 10. Terminología relacionada con la masturbación (ES).

En este campo temático hallamos 13 términos en inglés frente a 8 en español. Esta oscilación se debe a la presencia de eufemismos en inglés que han sido traducidos mediante un mismo término en la lengua meta, tal y como explicaremos a continuación. Por un lado, to flick the bean y to stroke a penis se trasfieren a español como masturbarse. Según nuestro sondeo, las dos expresiones usadas en la versión original se presentan al receptor como coloquiales o malsonantes, mientras que el ortofemismo empleado en el doblaje es considerado un verbo de uso normal o formal. Aunque nos encontramos ante un fenómeno totalmente opuesto al que hemos presenciado en las categorías anteriores, cabe mencionar que, a pesar de que la estructura española constituye un registro más formal que provoca una pérdida de comicidad, esta técnica denota una ausencia del tabú lingüístico en español, pues no se emplean sentidos figurados que eviten la obscenidad.

Además, la pérdida de informalidad no ocurre en la traducción de todos los términos hallados. Observamos que, en el caso de la terminología empleada para la masturbación femenina en inglés (to finger, to touch) se recurre a un disfemismo y a un eufemismo, respectivamente, mientras que en español ambas entradas quedan transferidas como dedos, reflejando un uso grotesco y desenfadado del lenguaje.

- Terminología relacionada con procesos de la sexualidad

\begin{tabular}{|l|r|r|r|r|r|}
\hline $\begin{array}{l}\text { Unidad } \\
\text { lingüística }\end{array}$ & Ofensivo & Malsonante/vulgar & Coloquial & Normal & Formal \\
\hline $\begin{array}{l}\text { To get an } \\
\text { erection }\end{array}$ & $0,8 \%$ & $1,7 \%$ & $5,8 \%$ & $37,2 \%$ & $54,5 \%$ \\
\hline To get hard & $0 \%$ & $9,1 \%$ & $62,8 \%$ & $28,1 \%$ & $0 \%$ \\
\hline $\begin{array}{l}\text { To pop the } \\
\text { cherry }\end{array}$ & $11,6 \%$ & $44,6 \%$ & $42,1 \%$ & $0,8 \%$ & $0,8 \%$ \\
\hline To skin the fish & $17,4 \%$ & $52,1 \%$ & $29,8 \%$ & $0,8 \%$ & $0 \%$ \\
\hline To come & $0 \%$ & $7,4 \%$ & $53,7 \%$ & $38 \%$ & $0,8 \%$ \\
\hline
\end{tabular}

Tabla 11. Terminología relacionada con procesos de la sexualidad (EN). 


\begin{tabular}{|l|r|r|r|r|r|}
\hline $\begin{array}{l}\text { Unidad } \\
\text { lingüística }\end{array}$ & Ofensivo & Malsonante/vulgar & Coloquial & Normal & Formal \\
\hline Empalmarse & $0 \%$ & $15,7 \%$ & $62 \%$ & $22,3 \%$ & $0 \%$ \\
\hline Desvirgar & $14,9 \%$ & $16,5 \%$ & $28,9 \%$ & $28,9 \%$ & $10,7 \%$ \\
\hline Desflorar & $15,7 \%$ & $15,7 \%$ & $22,3 \%$ & $14,9 \%$ & $31,4 \%$ \\
\hline Pelar la sardina & $14,9 \%$ & $51,2 \%$ & $32,2 \%$ & $1,7 \%$ & $0 \%$ \\
\hline Correrse & $2,5 \%$ & $76 \%$ & $14,9 \%$ & $0,8 \%$ & $0,8 \%$ \\
\hline
\end{tabular}

Tabla 12. Terminología relacionada con procesos de la sexualidad (ES).

En primer lugar, encontramos en inglés un ortofemismo (to get an erection) y un disfemismo (to get hard) considerados mayoritariamente por los encuestados como de uso formal y coloquial, respectivamente, y que han quedado traducidos mediante un mismo término coloquial (empalmarse).

Por otro lado, esta categoría se caracteriza por la recurrencia a disfemismos en ambas lenguas para describir el acto de perder la virginidad, con dos expresiones en inglés (to pop the cherry y skin the fish) y tres en español (desvirgar, desflorar y pelar la sardina). Merece especial mención la relación entre los equivalentes funcionales to pop the cherry y desvirgar o desflorar, donde sí se ha mantenido el uso del disfemismo en español. Conforme al sondeo realizado, el $44,6 \%$ de los participantes estima que to pop the cherry es una expresión malsonante o vulgar, seguido muy de cerca por el 42,1 \%, que la clasifica como coloquial. Por otra parte, los resultados obtenidos para el verbo desflorar resultan muy llamativos ya que, si bien el 31,4 \% lo califican como un verbo formal, el resto de los valores se dividen de forma equitativa entre quienes lo interpretan como un término ofensivo, vulgar y coloquial, por lo que no parece haber una apreciación clara que nos permita conocer el efecto que tiene en el público de la lengua meta. Esto nos hace pensar que, si bien esta palabra nació para emplearse en contextos formales, desflorar ha sufrido un proceso de banalización hasta tal punto en el que hoy parte de la población lo utiliza en situaciones comunicativas coloquiales.

Por último, consideramos oportuno detenernos a comentar la traducción del disfemismo to skin the fish, traducido al español como pelar la sardina. Esta traducción parece albergar un falso sentido pues, en el argot juvenil actual, su 
MARÍA DEL MAR OGEA POZO Y LARA HIDALGO BUJALANCE

atribuido equivalente al español pelar la sardina alude a la masturbación masculina y no a la virginidad. Por esta razón, sería más acertado utilizar otro tipo de expresiones que, aun alejándose del texto original, aportasen una mayor carga idiomática y más naturalidad en la lengua meta como, por ejemplo, estrenarse.

\section{Conclusiones}

La riqueza del ser humano como miembro de una comunidad reside en la interrelación de la capacidad del lenguaje, la lengua y el habla. Gracias a la confluencia de estos tres elementos tenemos la capacidad de originar, a través del código lingüístico, una identidad propia que es un reflejo de la sociedad y la cultura a la que pertenecemos. En un mundo globalizado donde conviven comunidades con las más diversas formas de comunicación y pensamiento, no es de extrañar que acaezcan choques culturales que, en ocasiones, se hacen patentes a través del lenguaje. A este fenómeno hemos de sumar que el sociolecto de los subgrupos que conforman una sociedad está en constante evolución y se muestra creativo ante la necesidad de denominar realidades interdictas.

El objetivo principal de este estudio ha sido comparar los distintos niveles de intensidad del lenguaje sexual presente en la lengua inglesa y en la lengua española mediante un estudio de caso. De este modo, hemos podido hallar divergencias entre ambos en lo concerniente al uso del vocabulario relacionado con la sexualidad, hecho que se justifica porque la recepción del lenguaje tabú depende de factores socioculturales.

A partir de los datos obtenidos en el estudio de recepción del producto audiovisual —en su versión original y en la versión doblada al español- entre el público español se ha procurado determinar en qué cultura se tiende a utilizar un registro lingüístico considerado por el público como más formal y en cuál, un registro más coloquial o incluso malsonante $u$ ofensivo. Para ello ha sido de gran utilidad el análisis y la clasificación de un total de 118 unidades lingüísticas pertenecientes a la serie de televisión juvenil Sex Education (2019). Los datos obtenidos de este procedimiento han sido realmente esclarecedores. 
A partir de los resultados podemos establecer que, a pesar de la existencia de expresiones y terminología propias del registro coloquial como to fuck o minge, a la hora de abordar temas de naturaleza sexual existe una clara tendencia por parte de la cultura británica a emplear eufemismos como to have sex y vagina y de disfemismos como to flick the bean, revelando así una preferencia por el discurso más atenuado incluso en las situaciones comunicativas más informales. En contraposición a esto, en el caso de la cultura española los resultados del análisis evidencian una predilección por parte de sus hablantes por el uso de un lenguaje de mayor carga emocional, el cual alberga expresiones más coloquiales, malsonantes $\mathrm{O}$, en definitiva, que resultan más intensas para el receptor, como es el caso de follar y coño. No obstante, en algunas ocasiones se recurre a ortofemismos como tener relaciones o vagina que rebajan el grado de informalidad de ciertos diálogos.

Ya que las unidades lingüísticas estudiadas han sido extraídas de una serie de televisión juvenil, podemos afirmar que este fenómeno no solo ocurre en situaciones reales y cotidianas entre la población más joven, sino que esto se traslada a producciones audiovisuales que pretenden reproducir este habla dinámica mediante el uso de expresiones coloquiales, vulgares, malsonantes u ofensivas que designan realidades cada vez menos tabuizadas en la sociedad contemporánea y, por ende, más presentes en el lenguaje. Dado que el cine ha de ser un reflejo de la sociedad, la disparidad entre el caso de la cultura británica y de la cultura española en lo que respecta al lenguaje sexual debe quedar patente en los diálogos que conforman la producción audiovisual doblada, con el objetivo de cumplir con las expectativas de la audiencia.

Es obvio que acceder a contenido audiovisual procedente de todo tipo de culturas resulta más sencillo que nunca para el usuario gracias al auge de las nuevas tecnologías y el nacimiento de las plataformas de contenido en streaming. Para que la experiencia del visionado sea satisfactoria, los traductores deben prestar especial atención a las convenciones lingüísticas y sociales de las culturas implicadas, lo que puede constituir un gran reto a la hora de conseguir naturalidad en el discurso. Asimismo, es preciso valorar el posible impacto provocado en los espectadores ante la presencia de contenido sensible. En algunos casos, será conveniente atenuar o intensificar el lenguaje, 
así como adaptar la terminología empleada al habla juvenil propia $-\mathrm{y}$ actualizada- de la cultura meta.

En lo referente a la traducción al español, hemos de resaltar la excelente labor de traducción llevada a cabo, pues se han respetado en todo momento las convenciones sociales de la cultura española y se ha optado por prescindir del registro formal o atenuado que en varias ocasiones estaba presente en la versión británica, algo que resultaría poco natural e impropio para los jóvenes españoles en ese tipo de situaciones comunicativas.

En conclusión, podemos decir sin temor a equivocarnos que Sex Education, al igual que otras series de tipo teen, es un reflejo de un sociolecto juvenil que cambia con cada generación. Para lograr el éxito de dicha serie tras ser importada a nuestro país, ha sido necesaria no solo una labor de transferencia lingüística sino cultural, a fin de adecuarla al habla de una generación joven que destaca por su gusto por lo emocional, la exaltación y, cada vez más, por la ausencia del tabú.

\section{Bibliografía}

ÁVILA CABRERA, José Javier (2015), «Propuesta de modelo de análisis del lenguaje ofensivo y tabú en la subtitulación», Verbeia: journal of English and Spanish studies, (0), pp. 8-27.

ALLAN, Keith y BURRIDGE, Kate (2006), Forbidden Words. Taboo and the Censoring of Language, Cambridge: Cambridge University Press

BERNAL MERINO, Miguel Ángel (2018), La traducción audiovisual: análisis práctico de la traducción para los medios audiovisuales e introducción a la teoría de la traducción filológica, Alicante: Publicacions Universitat Alacant.

CESTERO MANCERA, Ana María (2015), «La expresión del tabú: estudio sociolingüístico», Boletín de Filología, 50 (1), pp. 71-105

CHAUME VARELA, Frederic (2005), «Los estándares de calidad y la recepción de la traducción audiovisualı, Puentes, 6, pp. 5-12.

DÍAZ CINTAS, Jorge y REMAEL, Aline (2007), Audiovisual Translation: Subtitling, Manchester: St. Jerome.

GUARINOS, Virginia (2009), «Fenómenos televisivos 'teenagers': prototipias adolescentes en series vistas en España», Comunicar, 33 (17), pp. 203-211.

FERNÁNDEZ, Laura (2020), «Si ves 'Sex Education' solo por el sexo te pierdes una gran serien, El País, 26 de enero. En: <https://elpais.com/cultura/2020/01/24/television/1579883897_756440.htm 1> (Fecha de consulta: 14-septiembre-2021)

FUENTES LUQUE, Adrián (2015), «El lenguaje tabú en la traducción audiovisual: límites lingüísticos, culturales y sociales», E-Aesla, $\mathrm{n}^{\circ} 1$. 
INIGO ROS, Marta y WESTALL, Debra (1996), «The translation of Relaia in 'A Perfect World'» citado en PALENCIA VILLA, Rosa María (mayo de 2004), «El doblaje audiovisual, ¿̇barrera o puente en el diálogo multicultural? Problemas y propuestası, Comunicación llevada a cabo en la Universitat Autònoma de Barcelona, Barcelona.

KOTSCHI, Thomas, OESTERREICHER, Wulf y ZIMMERMANN, Klaus (1996), El español hablado y la cultura oral en España e Hispanoamérica, España: Instituto iberoamericano.

MAYO MARTíN, Paula (2018), «Estudio sobre expresiones metafóricas tabú de uso frecuente para su aplicación a la enseñanza de Español como Lengua Extranjera». En: DÍAZ FERRO, Marta, VAAMONDE, Gael, VARELA SUÁREZ, Ana, CABEZA PEREIRO, María del Carmen, GARCÍA-MIGUEL GALLEGO, José María y RAMALLO FERNÁNDEZ, Fernando (Eds.), Actas do XIII Congreso Internacional de Lingüística Xeral, pp. 600-606.

MITKOVA, Adriana (2007), «El léxico juvenil por áreas temáticas», Tonos. Revista electrónica de estudios filológicos, nº 14, Murcia: Universidad de Murcia.

PUJOL, Dídac (2006), «The Translation and Dubbing of 'Fuck' into Catalan: The Case of From Dusk till Dawnı, The Journal of Specialised Translation, $n^{\circ} 6$, pp. 121-133.

RAYA, Irene, SÁNCHEZ-LABELLA, Inmaculada y DURÁN, Valeriano (2018), «La construcción de los perfiles adolescentes en las series de Netflix Por trece razones y Atípicoı, Comunicación y medios, (37), pp. 131-143.

RODRÍGUEZ GONZÁLEZ, Félix (2002), «Lenguaje y contracultura juvenil: anatomía de una generación», en RODRÍGUEZ GONZÁLEZ, Félix (Coord.), El lenguaje de los jóvenes. Barcelona: Ariel, pp. 29-56.

SÁNCHEZ BENEDITO, Francisco (2005), «Eufemismo y fraseología sexual en inglés», en SANTAEMILIA RUIZ, José (Coord.), The language of sex, saying and not saying, València: Universitat de València, pp. 75-87.

SANTAEMILIA, José (2010), «Amor y erotismo en Vargas Llosa y su traducción al inglésı. Trans, Revista de Traductología, 0 (14), pp. 125-141.

SANTAEMILIA, José (2008), "The Translation of Sex-Related Language: The Danger(s) of Self-Censorship(s)». TTR, 21 (2).

SANTOS GARGALLO, Isabel (1997), «Algunos aspectos léxicos del lenguaje de un sector juvenil. Historias del Kronen de J.A: Mañas», Revista de filología románica, $\mathrm{n}^{\circ} 14,1$, pp. 455-474.

SURIÀ, Scheherezade (2014), "Sexo oral y escrito: argot, eufemismos y etimologíaı. En la luna de Babel [Blog], 15 de julio. En: < https://enlalunadebabel.com/2014/07/15/sexo-oral-y-escrito-argoteufemismos-y-etimologia/> (Fecha de consulta: 14-septiembre-2021).

VV. AA. (2021), Anuario de las artes escénicas, musicales y audiovisuales. En: <http://www.anuariossgae.com/home.html> (Fecha de consulta: 05septiembre-2021).

VV. AA. (2021), Diccionario de la Real Academia Española. En: <https://dle.rae.es/diccionario> (Fecha de consulta: 28-agosto-2020).

ZIMMERMANN, Klaus (1996), «Lenguaje juvenil, comunicación entre jóvenes y oralidadı, en KOTSCHI, Thomas, OESTERREICHER, Wulf y ZIMMERMANN, Klaus (Coords.), El español hablado y la cultura oral en España e Hispanoamérica, Madrid: Iberoamericana, pp. 475-514.

ZORRILLA, Mikel (2015), «La evolución del sexo en el cine», Espinof, 9 de febrero. En: $\quad<$ https://www.espinof.com/diccionario-cine-television/la-evoluciondel-sexo-en-el-cine-i> (Fecha de consulta: 13-septiembre-2021). 
MARÍA DEL MAR OGEA POZO Y LARA HIDALGO BUJALANCE

LA TRADUCCIÓN DEL ARGOT SEXUAL EN SERIES JUVENILES: EL DOBLAJE DE SEX EDUCATION

\section{Material audiovisual}

NUNN, Laurie (2019). Sex Education (Temporada 1) [TV]. Reino Unido: Eleven Film. Distribuida por Netflix España. 